\title{
PATRONES DE LA VOTACIÓN DE MÉXICO EN LA ASAMBLEA GENERAL DE LA ONU ENTRE 1994 Y 2015: CUESTIONES DE ORIENTE MEDIO Y PALESTINA
}

\author{
Enrique Paredes Frías \\ Ezequiel Contreras Piña
}

AunQue en EL discurso oficial son frecuentes las referencias a los principios constitucionales de política exterior como elementos normativos del actuar internacional de México, ${ }^{1}$ no se definen ni en las leyes secundarias ni en jurisprudencia, y no hay un mecanismo legal que obligue al presidente (el encargado constitucional de dirigir la política exterior) a observarlos. De esta situación surge el cuestionamiento de si la política exterior mexicana se conduce de verdad conforme a esos principios.

Sobre esta cuestión, Ana Covarrubias concluyó que "un lenguaje de principios puede ser, como ha sido, una estrategia útil, pero lo que no es posible es reducir la política exterior a una política de principios, lo que en la práctica no ha sucedido". ${ }^{2}$ Rafael

${ }^{1}$ Los principios constitucionales de política exterior son: la autodeterminación de los pueblos; la no intervención; la solución pacífica de controversias; la proscripción de la amenaza o el uso de la fuerza en las relaciones internacionales; la igualdad jurídica de los estados; la cooperación internacional para el desarrollo; el respeto, la protección y promoción de los derechos humanos y la lucha por la paz y la seguridad internacionales. Véase Constitución Política de los Estados Unidos Mexicanos, artículo 89, México, Diario Oficial de la Federación, última reforma publicada el 27.I.2016.

2 "Los principios y la política exterior de México", en J. A. Schiavon, D. Spenser y M. Vásquez Olivera (eds.), En busca de una nación soberana. Relaciones internacionales de México, siglos XIX y XX, México, CIDE y SRE, 2006, pp. 387-422. 
Velázquez, a su vez, llamó ese actuar flexible "pragmatismo principista” y consideró que los diplomáticos dirigen la política exterior cotidianamente según los principios, hasta que presidencia toma el timón y se comporta siguiendo un interés específico. ${ }^{3} \mathrm{Al}$ observar ese uso discrecional, Andrés Ordóñez predijo el final del discurso, cuando concluye: "la rígida codificación doctrinaria se hará redundante y un día veremos la retórica de los principios desaparecer del texto constitucional". ${ }^{4}$ Por tanto, el presente artículo propone usar métodos cuantitativos para descifrar empíricamente (ya no desde los principios), las causas del actuar de México en un segmento delimitado de su política exterior: la votación sobre los temas de Oriente Medio y Palestina en la Asamblea General de la Organización de las Naciones Unidas (AGONU) en el periodo comprendido entre 1994 y 2015.

La delimitación del tema es útil tanto por el carácter reiterativo de las resoluciones de la AGONU, que facilita la identificación de cambios de postura sobre un mismo asunto en el transcurso del tiempo, como si se observa que el marco temporal abarca dos administraciones del Partido Acción Nacional (PAN) y una y media del Partido Revolucionario Institucional (PRI), lo que permite identificar cambio o continuidad en la alternancia. El periodo sirve también para observar en la AGONU la política exterior mexicana independiente que resultó de la "relación especial" con el vecino del norte, ${ }^{5}$ una situación que coincide temporalmente con el aislamiento de Estados Unidos (e Israel) en sus posiciones sobre cuestiones de Oriente Medio ${ }^{6}$ y con el alejamiento de los países

3 “«Pragmatismo principista»: la política exterior de México”, Revista de Relaciones Internacionales de la UNAM, núms. 120/121, 2014-2015, pp. 151-164.

${ }^{4}$ De los avatares de la soberanía. Tradición hispánica y pensamiento político en la vida internacional de México, México, SRE, 2005, p. 245.

${ }^{5}$ Más sobre la "relación especial" en J. A. Schiavon, "Los principios y la política exterior de México”, en J. A. Schiavon, D. Spenser y M. Vásquez Olivera (eds.), op. cit., pp. 423-462.

${ }^{6}$ Véase S. Y. Kim y B. Russett, "The new politics of voting alignment in the United Nations General Assembly”, International Organization, vol. 50, núm. 4, 1996, pp. 629-652. 
latinoamericanos de los previos consensos del bloque oeste de la Guerra Fría. ${ }^{7}$

$\mathrm{El}$ artículo se divide en tres partes. La primera, metodológica, explica qué es el Índice de Controversia (ICO) y cómo se elabora; la segunda muestra y estudia los resultados de la aplicación del ICo a todas las resoluciones catalogadas por Marín Bosch como Oriente Medio y Palestina; ${ }^{8}$ la tercera arroja conclusiones que permiten inducir qué votaciones apoyará México y en cuáles será más probable que se abstenga, independientemente de consideraciones de principios de política exterior.

En el periodo de estudio, México se encuentra inserto en un modelo político económico liberal, que en el caso de Oriente Medio implicó, cuando menos hasta el año 2000, un acercamiento a los países más ricos de la región, por lo regular encontrados en lados opuestos de las votaciones materia de estudio: Egipto, Arabia Saudita e Israel. ${ }^{9}$ Entre el $9 / 11$ y el 2006 , México se vio en un proceso de reacomodo para con la región donde tuvo que balancear su política regional tomando en cuenta su relación con Estados Unidos. Sin embargo, no fue sino hasta el sexenio de Felipe Calderón que se retomó activamente el enfoque económico, con la intención de diversificar el comercio y atraer inversiones mediante la apertura de representaciones en diversos países del Golfo Pérsico. ${ }^{10} \mathrm{La}$ estrategia de acercamiento económico ha tenido continuidad durante el sexenio de Enrique Peña Nieto.

${ }^{7}$ E. Voeten, "Resisting the lonely superpower: responses of states in the United Nations to U.S. Dominance”, The Journal of Politics, vol. 66, núm. 3, 2004, pp. 729-754.

${ }^{8}$ La clasificación que Marín Bosch esboza para las resoluciones establece los siguientes temas: Naciones Unidas, seguridad internacional y desarme, cuestiones políticas, cuestiones económicas, cuestiones sociales, codificación del derecho internacional, descolonización, Medio Oriente/Palestina y Sur de África. Véase su libro Votes Count: A Compilation of United Nations General Assembly (UNGA) resolutions and Votes of Member States, Desarmex, vol. 1, 2012, p. vi, en http://desarmex.org/ portal/, consultado el 20.X.2016.

${ }^{9}$ Para este asunto, véase H. Varela e I. I. Sánchez, “África y Medio Oriente”, en M. de Vega (coord.), Historia de las relaciones internacionales de México, 1821-2010, México, SRE, vol. 7, 2006, pp. 245-250.

${ }^{10}$ Cf. M. Tawil, "México ante Medio Oriente durante el gobierno de Felipe Calderón”, Foro Internacional, núms. 3/4, vol. 53, 2013, pp. 667-706. 


\section{Midiendo la votación de México en la agonu}

No pocos autores han estudiado las votaciones en la AGONU utilizando distintas variables: cooperación (ayuda) para el desarrollo, intenciones de firmar tratados, terrorismo y probabilidades de obtener préstamos del Fondo Monetario Internacional y del Banco Mundial, son algunos ejemplos. ${ }^{11}$ Para el caso de México, el antecedente cuantitativo obligatorio es el Índice de Coincidencia (IC), que mide el comportamiento de México en la AGONU tomando como referencia cómo votan otros países, grupos de Estados o el promedio de votantes. Haciendo uso de esa herramienta comparativa, Marín Bosch mostró en los patrones de votación algunas alianzas y desavenencias históricas, como las divisiones Norte-Sur y Este-Oeste. ${ }^{12}$

El presente artículo propone contribuir al análisis cuantitativo, midiendo la votación mexicana, ya no en comparación con la de otros estados o grupos, sino observando la resolución misma y la controversia que causó. La herramienta utilizada es el Ico y arroja, al igual que el Ic, valores entre cero y uno. Para graficar cómodamente, estos valores se multiplican por cien. La premisa sobre la cual se elaboró el ico es que si hay un número igual de votos Sí (s) y No (N), entonces hay controversia total y, por tanto, el valor de ICo es el máximo, es decir uno. Si sólo hay votaciones s, entonces hay mínima controversia y el valor será cero. ${ }^{13}$ En el periodo de estudio, no hubo ausencias sin que se haya hecho saber la intención de voto a posteriori y las abstenciones se estudiaron bajo las consideraciones de los párrafos siguientes.

${ }^{11}$ Un resumen sobre las obras, autores y enfoques puede encontrarse en M. Bailey, A. Strezhnev y E. Voeten, "Estimating Dynamic State Preferences from United Nations Voting Data", Journal of Conflict Resolution, 8 de febrero de 2015, pp. 1-36.

12 Véase su libro Votos y vetos en la Asamblea General de las Naciones Unidas, México, FCE, 2004, pp. 172-193.

13 Por cierto, los votos $\mathrm{N}$ son más interesantes para Marín Bosch, porque "votar en contra es a menudo una imperiosa necesidad, un acto de convicción (para los países grandes, medianos y pequeños) o el resultado de una presión bilateral de las naciones más grandes. Oponerse a la voluntad de la mayoría requiere, pues, de una decisión que puede acarrear ciertas consecuencias desagradables para el país en cuestión, sobre todo si se trata de uno relativamente pequeño (ibidem, pp. 127-128). 
Marín Bosch plantea que las abstenciones son una forma cómoda de posicionarse en un "limbo", ${ }^{14}$ lo que implica un desacuerdo atenuado o un impedimento interno. Dado que ello significa cierta controversia, el ICo se diseñó tomando en cuenta las abstenciones (A): si el número de votos $\mathrm{N}$ y s son iguales, se seguirá configurando el valor máximo de controversia (1), sin importar las abstenciones; el ICo rondará entre 1 y 0.5 , cuando las abstenciones superen los votos s; finalmente, el ICo tomará valores entre 0 y 0.5 , cuando los votos s superen las abstenciones. La fórmula se elabora así:

$$
I C o=\left\{\begin{array}{cc}
0 & S=N=0 \\
1-\frac{|S-N|}{S+N+A} & \text { en cualquier otro caso }
\end{array}\right.
$$

Siguiendo la citada clasificación de Marín Bosch, se actualizaron las resoluciones sobre Oriente Medio/Palestina hasta 2015; se les aplicó el ICo y se estudiaron las resoluciones más controvertidas y las abstenciones.

\section{LOS RESULTADOS}

En la gráfica 1 se observan todas las resoluciones clasificadas como Oriente Medio/Palestina con las abstenciones marcadas en negro. El resto de los votos fueron s y aparecen en gris. ${ }^{15}$ En general, al observar que el Ico promedio fue de 16.3, se puede afirmar que hubo cierto consenso. Sólo el 2.7\% de los votos fueron N y el 10.9\% abstenciones, mientras que el resto fueron votos $\mathrm{s} .{ }^{16}$

14 Ibid., p. 128.

${ }^{15}$ En todas las gráficas se seguirá el mismo código cromático.

${ }^{16}$ Kofi Annan afirma que el consenso en la AGONU sería positivo si reflejara que los estados tienen genuina unidad de propósito al responder a los retos globales. No obstante, considera que el consenso (que a menudo se interpreta como unanimidad) se ha convertido en un fin por sí mismo. Primero se busca en el nivel regional y después en la totalidad. Esto no ha sido efectivo para reconciliar los intereses de los estados miembro. En lugar de ello, la Asamblea acuerda generalidades y deja de lado cualquier esfuerzo serio de tomar medidas. Más sobre el 
En lo que atañe a México, es de apuntar que éste siempre vota a favor de las resoluciones que se encuentran en la parte baja y que la mayoría de las abstenciones se ubican arriba de la franja de 40, con la sola excepción de un voto que se encuentra en el rango de 30, específicamente en el punto 33.08. También son notorias las dos resoluciones más controvertidas, sobre las cuales México votó s. Entender esta tendencia a votar siempre afirmativamente en las resoluciones menos controvertidas y a abstenerse cuando la controversia aumenta, requiere desglosar las votaciones por tema y ver por qué en ocasiones México se abstiene y en qué casos sostiene sus votos s sin importar el grado de controversia. Para tales efectos se propone clasificar las resoluciones según su ICo: serán de controversia alta, cuando hayan subido de la franja de 50; media, cuando hayan alcanzado 30 , pero no 50 ; y baja, cuando no lleguen a 30 .

\section{GRÁFICA 1}

Votación de todos los temas de Medio Oriente/Palestina 1994-2015

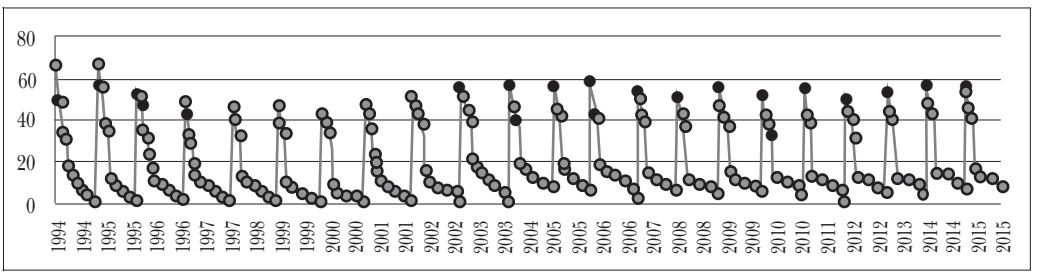

A continuación, veremos los casos en que México votó fuera del frecuente s y en lugar de ello se posicionó en el "limbo" de las abstenciones. Revisaremos los votos s que sostuvo en resoluciones de controversia alta y estudiaremos el caso de Líbano, cuyas resoluciones han sido de ICo alto, medio y bajo.

asunto en Annan, "In larger freedom A/59/2005", 21 de marzo de 2005, en http://www.un.org/en/ga/search/view_doc.asp?symbol=A/59/2005, consultado el 20.VI.2016. 


\section{Controversia alta}

En este rubro se ubican "El Golán sirio (ocupado)", "Labor del Comité especial encargado de investigar las prácticas israelíes que afecten los derechos humanos del pueblo palestino y otros habitantes árabes de los territorios ocupados", "Ataques israelíes contra Líbano y sus consecuencias", ${ }_{17}$ "Medidas ilegales israelíes en la Jerusalén Oriental ocupada y el resto del territorio palestino ocupado" y "El riesgo de proliferación nuclear en Oriente Medio".

El Golán sirio (ocupado). La decisión israelí de anexar oficialmente el Golán sirio fue condenada por la Organización de las Naciones Unidas (ONU), primero en el Consejo de Seguridad (CSONU), cuando estableció que la decisión era nula y sin efectos de acuerdo con el derecho internacional, exigiendo a Israel revocar la decisión. ${ }^{18}$ La condena en la AGONU vino en diciembre de 1982, cuando el órgano calificó la anexión como un acto de agresión contrario al principio de inadmisibilidad de la adquisición de territorio por la fuerza, al tiempo que definía a Israel como un Estado miembro que no era amante de la paz y que no cumplía con las decisiones de la onu. Por tanto declaró la ocupación sin validez ni efectos jurídicos y lamentó que Estados Unidos vetara una resolución para adoptar las medidas necesarias para hacer cumplir la resolución 497 del csonu, así como el apoyo político y militar del que gozaba la potencia ocupante. Finalmente exhortó a los estados miembros a suspender la asistencia militar, económica y cultural con Israel, a romper relaciones y, en términos generales, a aislarlo del marco internacional. ${ }^{19}$

${ }^{17}$ Esta resolución se tratará más adelante, en conjunto con "La situación de derechos humanos creada por las recientes operaciones militares israelíes en el Líbano" y "Marea negra en la costa libanesa".

18 CSONU, "Resolution 497", 1981, en https:/ / documents-dds-ny.un.org/doc/ RESOLUTION/GEN/NR0/418/84/IMG/NR041884.pdf?OpenElement, consultado el 22.VI.2016.

19 AGONU, "La situación en el Oriente Medio; El Golán sirio ocupado A/ RES/37/123”, 1982, en http://www.un.org/en/ga/search/view_doc.asp?symbol= A/RES/37/123\&referer=http://www.un.org/depts/dhl/resguide/r37_resolutions_table_eng.htm\&Lang=S, consultado el 22.VI.2016. 
En nuestro periodo de estudio hay dos tipos de resoluciones sobre este tema, cuyos comunes denominadores son: la preocupación por la irrupción en el Golán sirio, la aplicabilidad del IV Convenio de Ginebra y la necesidad de lograr una paz justa, general y duradera. La sutil diferencia entre ambos tipos es que unas resoluciones declaran que Israel no ha cumplido la resolución 497 del CSONU, ${ }^{20}$ mientras que las otras hacen un llamado a que la cumpla. ${ }^{21}$ Esta sutil diferencia, notable en la gráfica 2, es la que causa la controversia. Ello es particularmente interesante tomando en consideración que si año con año se insta al cumplimiento, es implícito que el contenido de la resolución sigue sin cumplirse. En los primeros años México votó a favor, cuando no hubo controversia y se abstuvo, cuando sí la hubo. A partir de 1998 la controversia bajó y México fijó su posición votando s.

GRÁFICA 2

El Golán sirio (ocupado)

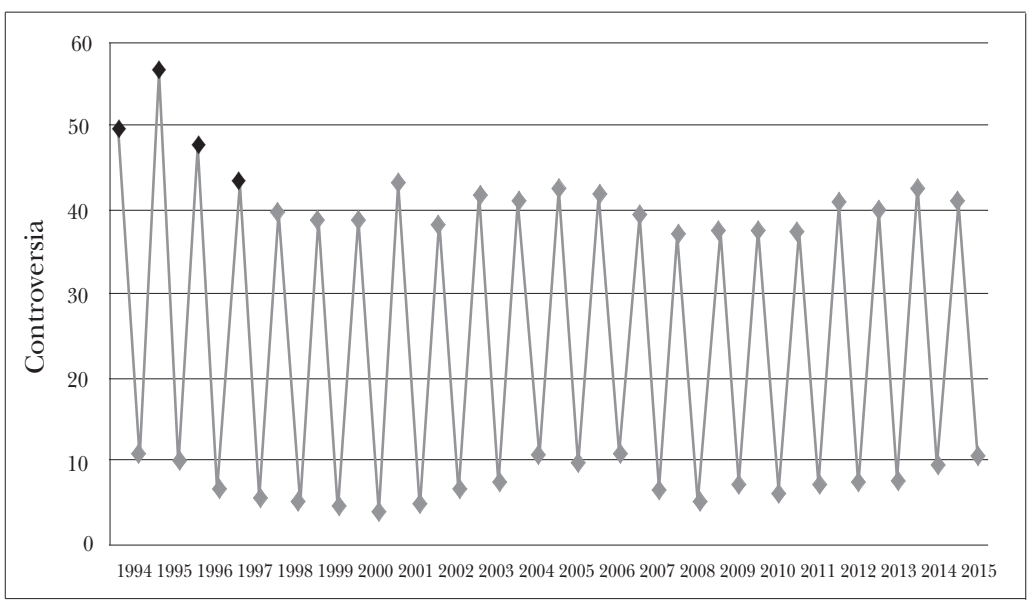

${ }^{20}$ AGONU, "El Golán sirio A/RES/69/25”, 2014, en http://www.un.org/es/ comun/docs/?symbol=A/RES/69/25, consultado el 6.VI.2016.

21 AGONU, "El Golán sirio ocupado A/RES/69/94", 2014, en http://www. un.org/es/comun/docs/?symbol=A/RES/69/94, consultado el 22.VI.2016. 
Por supuesto, Israel votó en contra de todas las resoluciones, lo cual no ha variado. Quien sí ha cambiado su votación, y junto con él un gran número de países, es Estados Unidos. En las resoluciones menos controvertidas Estados Unidos se abstuvo y un buen número de países votaron entonces a favor;22 cuando se opuso, un gran número de votantes se abstuvo, como en el caso de México entre 1994 y $1997 .{ }^{23}$

Labor del Comité especial encargado de investigar las prácticas israelies que afecten los derechos humanos del pueblo palestino y otros habitantes árabes de los territorios ocupados. El 19 de diciembre de 1968 la AGONU creó el "Comité especial...", solicitando a Israel que cooperara. ${ }^{24} \mathrm{~A}$ partir del siguiente año, el Comité comenzó a rendir informes periódicamente que hacen alusión a los castigos colectivos, los asentamientos, las acciones, que tienen como propósito alterar el carácter jurídico, geográfico y demográfico de los territorios ocupados, los detenidos arbitrariamente, ${ }^{25}$ el uso excesivo de la fuerza en contra de civiles palestinos, ${ }^{26}$ la destrucción generalizada de bienes e infraestructura esencial, especialmente en la franja de Gaza, ${ }^{27}$

${ }^{22}$ AGONU, “69a sesión plenaria A/52/PV.69”, 1997, en http:/ /www.un.org/en/ ga/search/view_doc.asp?symbol=A/52/PV.69\&referer=http:/ / www.un.org/depts/ $\mathrm{dhl} /$ resguide/r52_resolutions_table_eng.htm\&Lang=S, consultado el 23.VI.2016.

${ }^{23}$ AGONU, "68 ${ }^{a}$ sesión plenaria A/52/PV.68”, 1997, en https://documents-ddsny.un.org/doc/UNDOC/GEN/N97/867/25/PDF/N9786725.pdf?OpenElement, consultado el 23.VI.2016.

${ }^{24}$ AGONU, "Respeto y aplicación de los derechos humanos en los territorios ocupados A/RES/2443 (XXIII)", 1968, en https://unispal.un.org/DPA/DPR/uni spal.nsf/0/1FE2116573C8CFBE852560DF000ED05D, consultado el 25.IX.2016.

${ }^{25}$ AGONU, "Labor del Comité especial encargado de investigar las prácticas israelíes que afecten a los derechos humanos del pueblo palestino y otros habitantes árabes de los territorios ocupados A/RES/49/36”, 1994, en http://www.un. org/documents/ga/res/49/a49r036.htm, consultado el 25.IX.2016.

${ }^{26}$ AGONU, "Labor del Comité especial encargado de investigar las prácticas israelíes que afecten a los derechos humanos del pueblo palestino y otros habitantes árabes de los territorios ocupados A/RES/55/130”, 2001, en http:/ / repository. un.org/bitstream/handle/11176/153515/A_RES_55_130-ES.pdf?sequence=6\&is Allowed=y, consultado el 25.IX.2016.

27 AGONU, "Labor del Comité especial encargado de investigar las prácticas israelíes que afecten a los derechos humanos del pueblo palestino y otros habitantes árabes de los territorios ocupados A/RES/64/91”, 2009, en https://unispal. 
los actos de violencia, intimidación y provocación cometidos por los colonos israelíes contra los civiles palestinos y sus bienes, incluidas viviendas, mezquitas, iglesias, y tierras de cultivo, ${ }^{28}$ y a la ocupación como una violación grave y flagrante de los derechos humanos. Año con año, la Asamblea General ha solicitado al Comité que continúe rindiendo sus informes al Secretario General de la ONU. ${ }^{29}$

\section{GRÁFICA 3}

Labor del Comité especial...

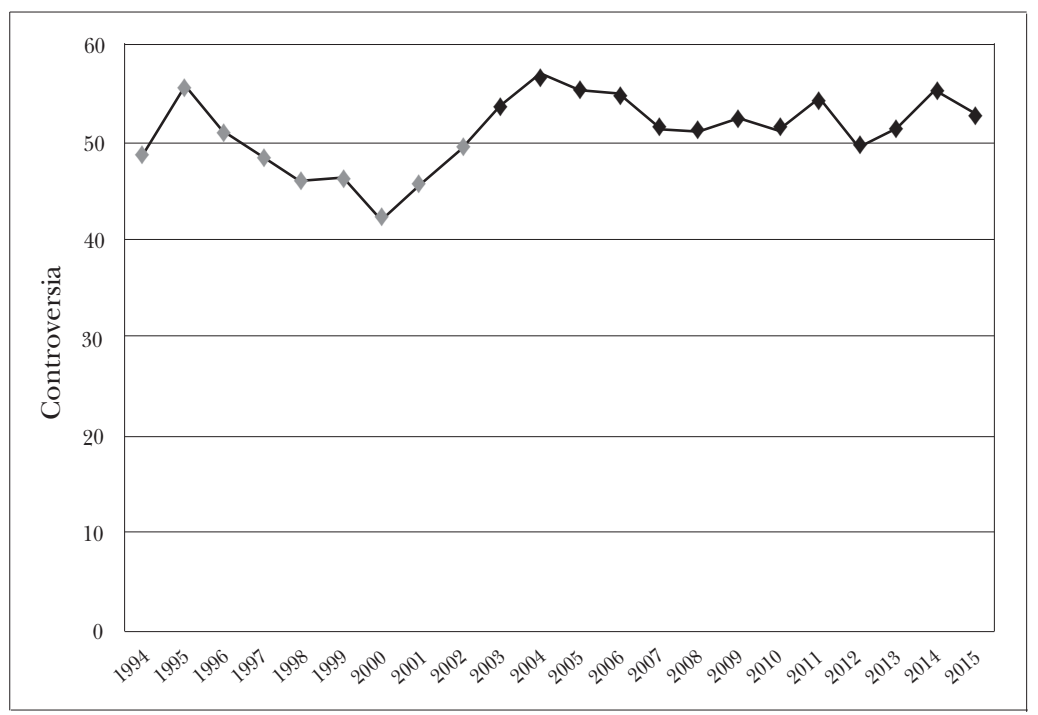

un.org/DPA/DPR/unispal.nsf/0/544BEB06378BA234852576B700700B02, consultado el 25.IX.2016.

${ }^{28}$ AGONU, "Labor del Comité especial encargado de investigar las prácticas israelíes que afecten a los derechos humanos del pueblo palestino y otros habitantes árabes de los territorios ocupados A/RES/67/118”, 2012, en https://unispal. un.org/DPA/DPR/unispal.nsf/0/F5E36EFEC44C5E9585257AF60059267A, consultado el 25.IX.2016.

${ }^{29}$ AGONU, "Labor del Comité especial encargado de investigar las prácticas israelíes que afecten a los derechos humanos del pueblo palestino y otros habitantes árabes de los territorios ocupados A/RES/69/90", 2014, en http://www.un.org/ en/ga/search/view_doc.asp?symbol=A/RES/69/90, consultado el 25.IX.2016. 
El comportamiento de México confirma la tendencia a abstenerse, cuando se suscita mayor controversia acerca de los principios de política exterior, ya que las abstenciones coinciden más o menos con la apertura de México a los mecanismos de derechos humanos y no cambian después de la reforma de $2011,{ }^{30}$ que, entre otras cuestiones, elevó a rango constitucional el principio de "la protección y promoción de los derechos humanos". Cualitativamente, las votaciones a favor se podrían explicar aduciendo que según la opinión popular nacional, México debería apoyar la promoción de los derechos humanos desde los foros multilaterales sin influir directamente en otros estados, ${ }^{31}$ aunque el límite a esta posición se encuentra en la controversia de la resolución.

Medidas ilegales israelies en la Jerusalén Oriental ocupada y el resto del territorio palestino ocupado. Las resoluciones acerca de este tema son las que se adoptan en las sesiones de emergencia de la AGONU, normalmente a partir de las recurrentes escaladas en el conflicto palestino-israelí. Ello significa que las votaciones versan sobre cuestiones diferentes (aunque relacionadas), lo que a su vez implica diferentes redacciones de los documentos e imposibilidad de emitir resoluciones reiterativas, como sucede en otros temas. Lo anterior explica el comportamiento aparentemente aleatorio del Ico en el tiempo y la falta de continuidad en las resoluciones.

${ }^{30}$ Para más información sobre la apertura a los derechos humanos y la reforma de 2011, consúltese N. Saltalamacchia Ziccardi y A. Covarrubias Velasco, "La dimensión internacional de la reforma de derechos humanos: antecedentes históricos”, en M. Carbonell y P. Salazar (coords.), La reforma constitucional de derechos humanos: un nuevo paradigma, México, Instituto de Investigaciones Jurídicas UnAM, 2011, pp. 1-38.

31 Según una encuesta publicada en 2006 por el Centro de Investigación y Docencia Económicas (CIDE) y el Consejo Mexicano de Asuntos Internacionales (Comexi), el 85\% de los líderes y el 86\% del público opinaron que era "muy importante" o "algo importante" promover los derechos humanos en el mundo, como objetivo de política exterior, aunque ante la pregunta “¿Qué cree usted que debe hacer México frente a un país en el que no se respeten los derechos humanos?”, el $48 \%$ del público opinó que debe impulsar que organismos como la onU censuren tales violaciones a los derechos humanos; el 28\%, que no debe entrometerse en los asuntos internos del país implicado, y sólo el 18\% opinó que deberían romperse las relaciones diplomáticas (ibid.). 


\section{GRÁFICA 4}

Medidas ilegales israelíes en la Jerusalén Oriental ocupada y el resto del territorio palestino ocupado

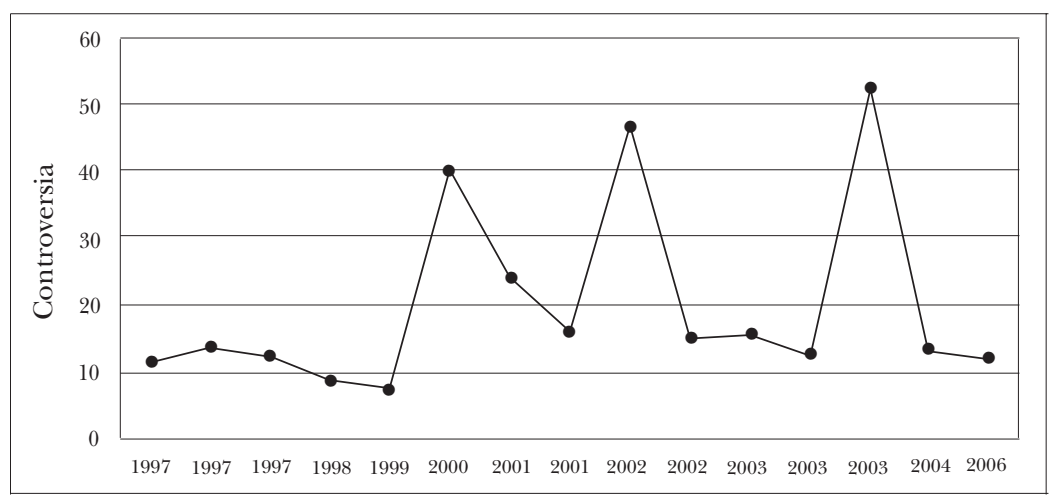

Contrario a la tendencia de abstenerse ante resoluciones controvertidas, México votó a favor en la resolución que estuvo por arriba de la franja de 50. En esa ocasión, la AGONU decidió solicitar a la Corte Internacional de Justicia (CIJ) su opinión consultiva respecto a la construcción del muro en la frontera unilateralmente establecida por Israel. La controversia (documentada en los debates de la resolución) responde a que un grupo de países consideraba que someter la opinión a la CIJ limitaría las posibilidades de que la cuestión se resolviera en el marco de un proceso de paz (Reino Unido) y que no era conveniente someter a criterios legales una cuestión con una carga política tan pesada (Canadá). La posición de Israel fue que la resolución carecía de fondo al haber sido promovida por Libia, a la que sarcásticamente calificaba de "gran bastión de la democracia y los derechos humanos" y por Siria, a la que describió como uno de los países "que ejecuta, acoge, financia e inicia el terror”. El representante israelí consideró que la votación reflejaba una división en que se encontraban, por un lado, 90 de los regímenes más tiránicos del mundo, que apoyaban la resolución y, por el otro, las democracias más iluminadas, 
es decir los 74 que se abstuvieron y los 7 que votaron, junto a él, en contra. ${ }^{32}$

México fue de los que apoyaron la resolución; las razones ciertamente fueron internacionales, pero estaban más relacionadas con los Estados Unidos que con Oriente Medio. Al llegar al poder, el gobierno de Fox (2000-2006) propuso una mayor integración con Estados Unidos, algo que llamó "NAFTA plus". Visualizando una integración al estilo Unión Europea (UE), una de las ideas era que, habiéndose permitido el libre tránsito de bienes y mercancías, era momento de facilitar el movimiento de personas. George Bush, también recientemente electo, parecía estar de acuerdo con ello, cuando ambos presidentes se reunieron en Guanajuato al comenzar el año de 2001. Los dos coincidieron en que trabajarían para crear una comunidad económica norteamericana y en que el tema de la migración sería un buen punto de partida. Los objetivos de México consistían en que los Estados Unidos regularizaran a los mexicanos indocumentados, facilitaran el proceso de visas, expandieran el programa de visas de trabajo temporal, que ambas naciones cooperaran en temas de seguridad en la frontera, incluidas las labores de asistencia a mexicanos en riesgo de perder la vida en el desierto, narcotráfico, y finalmente que se promoviera el desarrollo económico en las regiones expulsoras de migrantes de México (algo parecido a los fondos europeos de cohesión). Todo esto quedó congelado después del 9/11 y comenzó a imperar la agenda de seguridad. ${ }^{33}$

En un contexto totalmente diferente, Israel construía un muro que en ocasiones fue justificado (no por el Estado, pero sí por sus simpatizantes), haciendo referencia a la reja fronteriza entre los Estados Unidos y México, ${ }^{34}$ que busca precisamente restringir el

32 AGONU, “A/ES-10/PV.23”, 2003, en https://documents-dds-ny.un.org/ doc/ UNDOC/GEN/N03/644/30/PDF/N0364430.pdf, consultado el 20.VI.2016.

${ }^{33}$ Ante la nueva situación, México no dejó de abogar discursivamente por el desplazamiento de personas, aunque en la práctica terminó adoptando políticas de potenciación de remesas. Véase M. Baker, "Migration Management in North America”, en M. Geiger y A. Pécoud (eds.), The Politics of International Migration Management, Londres, Palgrave Mcmillan, 2010, pp. 271-294.

${ }^{34}$ Cf. M. Bard, "West Bank Security Fence: Background and Overview", Jewish Virtual Library, 2016, en http://www.jewishvirtuallibrary.org/jsource/Peace/fence.html, consultado el 20.VI.2016. 
movimiento de personas, y que Fox buscaba fomentar. Era natural que México se quisiera desasociar de cualquier medida de ese tipo y que apoyara una resolución evidentemente cargada en contra de la construcción del muro. Irónicamente, en 2014 una de las compañías israelíes que monitorean las "fronteras" entre Gaza y la Ribera Occidental ganó un contrato para construir un muro virtual en Arizona, parte de la frontera entre México y los Estados Unidos. ${ }^{35}$

El riesgo de proliferación en Oriente Medio. Cada año, en el seno de la AGONU se adopta una resolución recordando que Israel es el único país de Oriente Medio que no es parte del Tratado de no proliferación nuclear (TNP), reafirmando la importancia de que lo adopte y exhortándolo a que renuncie a la posesión de armas nucleares. ${ }^{36}$ Como se verá en adelante, la cuestión nuclear es un tema de particular importancia para México, por lo que en los dos años en que las resoluciones estuvieron por arriba de la línea de los sesenta México votó a favor. El punto que dividió las opiniones en las resoluciones controvertidas fue el señalamiento específico a Israel, pues había otros países en la región que tampoco eran parte del TNP.

En 1994, el representante de Botsuana expresó la situación en los siguientes términos:

Aunque mi delegación votará a favor del borrador de resolución [...] estamos obligados a cuestionar lo justo del párrafo operativo primero. Hubiéramos deseado que el párrafo mencionara por su nombre, si nombrar fuera necesario, a todos los Estados de los que se sospecha que desarrollan, producen, prueban o intentan adquirir armas nucleares. ${ }^{37}$

35 Véase T. Miller y G. M. Schivone, "Why is an Israeli Defense Contractor Building a «Virtual Wall» in the Arizona Desert?”, The Nation, 2015, en http:/ /www. thenation.com/article/why-israeli-defense-contractor-building-virtual-wall-arizo na-desert/, consultado el 20.VI.2016.

${ }^{36}$ AGONU, "El riesgo de proliferación nuclear en el Oriente Medio A/RES/69/ 78”, 2014, en http://www.un.org/es/comun/docs/?symbol=A/RES/69/78, consultado el 20.VI.2016.

37 AGONU, "El riesgo de proliferación nuclear en el Medio Oriente A/49/ PV.90”, 1994, en https:/ / documentsddsny.un.org/doc/UNDOC/GEN/N94/874/ 79/PDF/N9487479.pdf?OpenElement, consultado el 20.VI.2016. 
GrÁficA 5

El riesgo de proliferación nuclear en el Oriente Medio

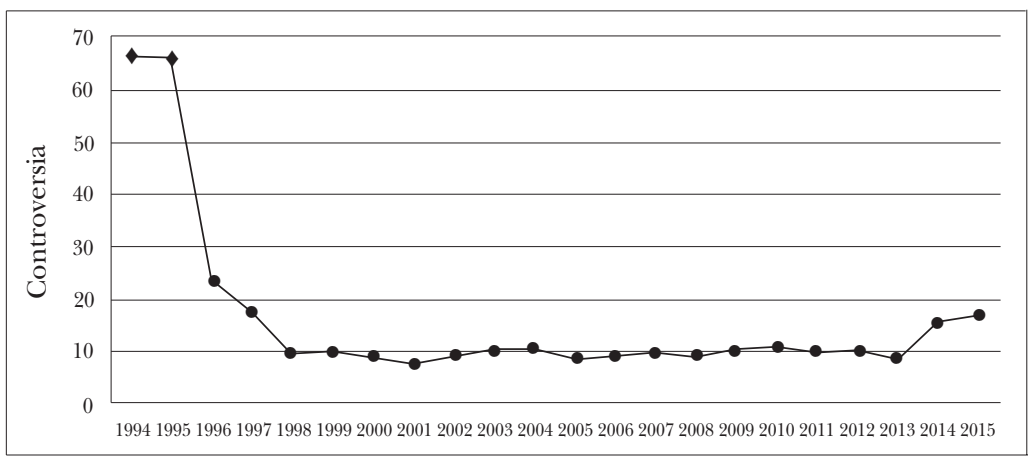

En ese párrafo, la AGONU

insta a Israel y a todos los demás Estados de la región que aún no sean parte en el Tratado sobre la no proliferación de las armas nucleares a que no desarrollen, produzcan, ensayen ni adquieran de otra forma armas nucleares, a que renuncien a la posesión de esas armas y a que se adhieran al Tratado. ${ }^{38}$

Una posición semejante expresó Nueva Zelandia en 1995: "Reafirmamos la importancia de la adherencia universal al tratado y llamamos a todos los Estados en Oriente Medio que no se han adherido a que lo hagan tan rápido como sea posible". ${ }^{39}$ Notamos que la resolución señala específicamente a Israel. Desde nuestro punto de vista, esto es inapropiado. Como hemos mencionado, Nueva Zelandia llama a todos los Estados que no son parte en la región, y en todo el mundo, a unirse a la gran mayoría de la comunidad inter-

38 AGONU, "El riesgo de proliferación en el Oriente Medio A/RES/49/78", 1994, en http://www.un.org/es/comun/docs/?symbol=A/RES/49/78, consultado el 20.VI.2016.

39 AGONU, "El riesgo de proliferación nuclear en el Oriente Medio A/50/ PV.90”, 1995, en https://documentsddsny.un.org/doc/UNDOC/GEN/N95/870/ 13/PDF/N9587013.pdf?OpenElement, consultado el 20.VI.2016. 
nacional que ve el TNP como la base desde la cual se debe trabajar para lograr un futuro libre de armas nucleares.

Este punto de controversia se fue quedando sin fondo conforme los últimos Estados en la región que no se habían adherido al TNP lo hicieron. En 1995, los Emiratos Árabes Unidos se unieron, ${ }^{40}$ y en octubre de 1996, el ministro de relaciones exteriores de Omán indicó la voluntad de su gobierno de acceder al tratado, ${ }^{41}$ lo cual dejó a Israel como el único estado en la región sin formar parte y cuya consecuencia fue una nueva redacción. Ésta insta al único estado de la región que aún no es parte en el Tratado y que no ha declarado su intención de serlo a que se adhiera a la mayor brevedad y a que no desarrolle, fabrique, ensaye o adquiera de cualquier otra forma, armas nucleares, y a que renuncie a la posesión de éstas, y a que someta todas sus instalaciones nucleares a las salvaguardias totales del Organismo internacional de energía atómica, como medida para fomentar la confianza entre todos los estados de la región y un paso hacia el fortalecimiento de la paz y la seguridad. ${ }^{42}$

El comportamiento de México en este asunto se puede explicar remontándose a la firma del Tratado de Tlatelolco de 1967. La idea de una zona libre de armas nucleares en América Latina había surgido en primera instancia de Costa Rica en una reunión de la OEA en 1958, que posteriormente fue retomada por el delegado de Brasil ante la onu poco antes de la crisis de los misiles de Cuba en 1962 y que fue impulsada con mayor vehemencia durante ese episodio de la Guerra Fría. México tomó la batuta bajo el liderazgo de Alfonso García Robles (embajador de México ante Brasil) y al año siguiente anunció que cinco países de América Latina estaban

${ }^{40}$ AGONU, "El riesgo de proliferación nuclear en el Oriente Medio A/RES/ 51/48", 1996, en http://www.un.org/es/comun/docs/index.asp?symbol=A/RE S/51/48\&referer=http://www.un.org/es/documents/ag/res/51/list51.htm\&Lan $\mathrm{g}=\mathrm{S}$, consultado el 20.VI.2016.

${ }^{41}$ AGONU, "General debate on all disarmament and international security items A/C.1/51/PV.12”, 1996, en https://documents-dds-ny.un.org/doc/UNDOC/GEN /N96/866/11/PDF/N9686611.pdf?OpenElement, consultado el 20.VI.2016.

${ }^{42}$ AGONU, "El riesgo de proliferación nuclear en el Oriente Medio A/RES/ 51/48". 
preparados para materializar la idea: Bolivia, Brasil, Chile, Ecuador y México. ${ }^{43}$

A partir de 1964 se comenzaron a celebrar las reuniones para la desnuclearización de la región en la Ciudad de México, ${ }^{44}$ que fueron todas presididas por Alfonso García Robles. ${ }^{45}$ En 1967, se firmó el tratado en las oficinas de la Secretaría de Relaciones Exteriores (SRE) en Tlatelolco ${ }^{46}$ y el Secretariado del Organismo para la Proscripción de las Armas Nucleares en América Latina (OPANAL) se estableció en la capital mexicana. Por sus actividades detrás de la organización de la conferencia, García Robles obtuvo el Premio Nobel de la Paz (que compartió con la sueca Alva Myrdal) en $1982 .{ }^{47}$

La firma del Tratado de Tlatelolco redituó en prestigio internacional para México, que participó activamente en las conferencias quinquenales del TNP en 1975, 1980, 1985 y en 1990, cuando se acordó la prórroga indefinida del tratado. ${ }^{48}$ También en 1991 Argentina y Brasil, los dos grandes estados en conflicto en América del Sur con algunas capacidades nucleares, firmaron en Guadalajara, México, un acuerdo bilateral de salvaguardias previo a la ratificación del Tratado de Tlatelolco y el TNP. ${ }^{49}$ Este activismo, que puso a México bajo la lupa internacional, lo obliga políticamente a mantener una postura acorde en los foros multilaterales.

${ }^{43}$ Véase I. Bellany, Curbing the Spread of Nuclear Weapons, Manchester, University Press, 2006, pp. 108-113.

${ }^{44}$ Alfonso García Robles fue nombrado subsecretario de relaciones exteriores los primeros meses de 1964, con lo que culminó su periodo como embajador ante Brasil.

${ }^{45}$ Cf. M. Marín Bosch, "Relatos e historias en México", Editorial Raíces S.A. de C.V., 2015, pp. 57-59.

${ }^{46}$ I. Bellany, op. cit. pp. 108-113.

${ }^{47}$ Centro de Información onu, "México y la onU”, 2004, en http:/ / www.cinu. org.mx/onu/mexico.htm, consultado el 20.VI.2016.

${ }^{48}$ M. Marín Bosch, "México en las negociaciones de desarme: la Conferencia de Desarme de Ginebra”, Revista Mexicana de Política Exterior, noviembre-febrero de 2001-2002, pp. 43-64.

${ }^{49}$ I. Bellany, op. cit. pp. 108-113. 
Abstenciones de México en resoluciones de controversia media

Hubo tres resoluciones de controversia media en las que México se abstuvo: "La situación de los niños palestinos y la asistencia a esos niños", que se votó en tres ocasiones, "La situación de derechos humanos creada por las recientes operaciones militares israelíes en el Líbano", que sólo se votó en una ocasión, y el "Seguimiento del informe de la Misión de Investigación de las Naciones Unidas sobre el conflicto en Gaza", que se votó en dos sesiones.

La situación de los niños palestinos y la asistencia a esos niños. La agudización de la Segunda Intifada provocó en la AGONU una preocupación particular por la situación de los niños palestinos y la asistencia a esos niños. Las resoluciones hacen notar el deterioro de sus condiciones de vida y exigen a Israel como potencia ocupante que respete la Convención sobre los Derechos del Niño y llaman a la comunidad internacional a prestarles asistencia. ${ }^{50}$

Para analizar el comportamiento de México en esta votación conviene observar una maniobra diplomática. En 2002 y 2003, Israel adoptó su tradicional postura de voto en contra, pero en 2004 el Estado judío fue más allá. Cuando se sometió la resolución a votación, solicitó que también se hiciera referencia a los niños israelíes, ya que alrededor de 100 habían muerto a causa del terrorismo palestino, en contraste con los aproximadamente 800 niños palestinos. ${ }^{51} \mathrm{Al}$ ser rechazada su propuesta, sometió a consideración una resolución independiente, haciendo referencia al sufrimiento de los niños israelíes. Aunque la propuesta no prosperó, el

${ }^{50}$ La primera resolución es AGONU, "La situación de los niños palestinos y la asistencia a esos niños A/RES/57/188”, 2002, en https://documents-dds-ny. un.org/doc/UNDOC/GEN/N02/550/73/PDF/N0255073.pdf, consultado el 21.VI.2016. La segunda, AGONU, "La situación de los niños palestinos y la asistencia a esos niños A/RES/58/155”, 2003, en https://documents-dds-ny.un.org/ doc/UNDOC/GEN/N03/503/91/PDF/N0350391.pdf, consultado el 21.VI.2016. La última fue AGONU, "La situación de los niños palestinos y la asistencia a esos niños A/RES/59/173", 2004, en https://documents-dds-ny.un.org/doc/UNDOC/GEN/N04/486/67/PDF/N0448667.pdf, consultado el 21.VI.2016.

51 Véase If Americans knew, "Israelis and Palestinians killed in the current violence", en http://www.ifamericansknew.org/stat/deaths.html, consultado el 21.VI.2016. 
punto había quedado claro, pues se estaban ignorando las bajas israelíes. ${ }^{52}$ Ese año la ue emitió un comunicado en que explicaba la abstención de los países de su grupo y condenaba tanto las prácticas israelíes en los territorios ocupados como los ataques terroristas que afectan a los niños israelíes. ${ }^{53}$ México, que había asumido una postura similar en sus debates en el csONU unos meses antes, se unió al grupo de países que se abstuvieron por los mismos motivos (véase gráfica 6). Específicamente, el jefe de la delegación mexicana establecía:

\section{GRÁFICA 6}

La situación de los niños palestinos y la asistencia a esos niños

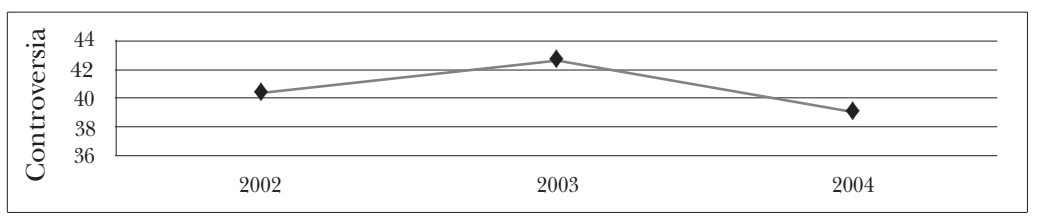

Lamentamos profundamente que la Autoridad Palestina no haya tenido hasta ahora ni la fuerza ni la cohesión, y, en última instancia, tampoco la determinación de detener los ataques terroristas y los atentados suicidas que tanto dolor, horror y sangre han causado a la población israelí, principalmente a la población civil inocente. En efecto, la gran mayoría de las víctimas de estos ataques son israelíes inocentes -niños, jóvenes, mujeres y ancianos-, muchos de ellos genuinamente convencidos de que Israel y Palestina deben y pueden

${ }^{52}$ Cf. American Jewish Committee, "One sided: The relentless campaign against Israel in the United Nations; A report on 2004-2005 General Assembly resolutions on the Arab-Israeli conflict”, Nueva York, 2005, en http://www.ajc.org/atf/ cf/\%7B42D75369-D582-4380-8395-D25925B85EAF\%7D/One_Sided_59th_Session_UNGA.pdf, consultado el 21.VI.2016.

${ }^{53}$ EU Delegation to the United Nations, "EU Presidency Statement - Situation of and assistance to Palestinian children”, 2004, en http://eu-un.europa.eu/eupresidency-statement-situation-of-and-assistance-to-palestinian-children/, consultado el 21.VI.2016. 
vivir en paz y prosperar juntos. Cada ataque terrorista suicida es un acto de autoinmolación de la causa palestina [...]. Nada gana Israel transitando por la ruta de las represalias desproporcionadas con grave pérdida de vidas humanas. Nada gana haciendo imposible la vida para los palestinos en su propio territorio. Nada gana llevando a condiciones humanitarias extremas a jóvenes y a niños palestinos. Nada gana con las ejecuciones extrajudiciales. Nada gana con la construcción de murallas. Estas medidas están muy lejos de lograr sus objetivos de seguridad. ${ }^{54}$

Seguimiento del informe de la Misión de Investigación de las Naciones Unidas sobre el conflicto en Gaza. El informe al que se refieren estas resoluciones es el comúnmente llamado "Reporte Goldstone", que fue presentado por el Consejo de Derechos Humanos de la ONU a la AGONU en 2009, después de la "Operación plomo fundido”, una de muchas incursiones militares israelíes en Gaza. El informe concluyó que ambas partes habían violado la ley humanitaria internacional en perjuicio de la población civil. ${ }^{55}$ Hubo dos resoluciones que dieron seguimiento al informe, ${ }^{56}$ solicitando a ambas partes que investigaran las violaciones a derechos humanos y al derecho internacional humanitario que establecía el informe, y llamando Suiza a que se convocara a una reunión de las partes contratantes del Convenio de Ginebra relativo a la protección debida a las personas civiles en tiempo de guerra (de 12 de agosto de 1949). 57

54 Instituto Matías Romero, Voz de México en el Consejo de Seguridad de la ONU 1946-2008, México, SRE, t. 2, 2009, pp. 204-206.

${ }^{55}$ Cf. I. Rabinovich, Lingering Conflict: Israel, The Arabs, and the Middle East 1948-2012, Washington DC, Brookings Institution Press, 2012, pp. 197-200.

${ }^{56}$ El ICo de la primera resolución (2009) fue 45.5; el de la segunda (2010), 33.

${ }^{57}$ La primera resolución es AGONU, "Seguimiento del informe de la Misión de Investigación de las Naciones Unidas sobre el Conflicto de Gaza A/RES/64/10", 2009, en http://www.un.org/en/ga/search/view_doc.asp?symbol=A/RES/64/10 \&referer=http://www.un.org/en/ga/64/resolutions.shtml\&Lang=S, consultado el 21.V.2016. La otra resolución es AGONU, "Segundo seguimiento del informe de la Misión de Investigación de las Naciones Unidas sobre el Conflicto de Gaza A/ RES/64/254", 2010, en http://www.un.org/en/ga/search/view_doc.asp?symbol= A/RES/64/254\&referer=/english/\&Lang=S, consultado el 21.VI.2016. 
Ante estas dos resoluciones (sobre el mismo tema), México votó a favor primero y con una abstención después. Llama la atención el cambio de postura por el hecho de que sólo transcurrieron tres meses entre una y otra, pero también porque en la primera ocasión la delegación mexicana participó activamente en el debate. El Embajador Claude Heller, que la presidía, intervino para afirmar que:

La consideración de este informe nos recuerda que la reanudación de las pláticas de paz sobre el conflicto en el Oriente Medio no puede demorarse nuevamente y tampoco debe quedar supeditada a nuevas precondiciones. El objetivo conocido por todos es claro: lograr una solución integral y definitiva al conflicto en el Oriente Medio que reafirme el reconocimiento del derecho a la existencia de Israel y permita el establecimiento de un Estado palestino política y económicamente viable que conviva en paz con Israel dentro de fronteras seguras e internacionalmente reconocidas, de conformidad con las resoluciones del Consejo de Seguridad, la Hoja de Ruta, los Principios de Madrid y la Iniciativa de Paz Árabe. Hoy tenemos la oportunidad de servir tanto a la paz como a la justicia internacional. No dejemos pasar esta oportunidad única. ${ }^{58}$

El punto que causó controversia fue que para un grupo de países (Rusia, Estados Unidos, Canadá y Australia, entre otros) el informe Goldstone estaba cargado de un lado. México también lo consideró así (al menos discursivamente), pero justificó su votación a favor de la siguiente manera:

México reitera su convicción de apoyar los esfuerzos de las Naciones Unidas para garantizar la rendición de cuentas por las violaciones de las normas internacionales de derechos humanos y del derecho internacional humanitario. Nuestro voto es un voto a favor de la rendi-

58 AGONU, "Seguimiento del informe de la Misión de Investigación de las Naciones Unidas sobre el conflicto en Gaza A/64/PV.39”, 2009 en http://www.un.org/ en/ga/search/view_doc.asp?symbol=A/64/PV.39\&referer=http://www.un. org/en/ga/64/resolutions.shtml\&Lang=S, consultado el 21.VI.2016. 
ción de cuentas, no de todas las recomendaciones contenidas en este informe. ${ }^{59}$

Otro punto de controversia en ambas resoluciones fue que no era claro quién sería el encargado por parte de Palestina de llevar a cabo las investigaciones, pues la AP había sido expulsada de Gaza en 2007. Sin intervenir en la segunda sesión sobre el tema, México se abstuvo.

El cambio de postura, errático si se lee al margen de los hechos, respondía a la necesidad de armonizar las votaciones de México en Naciones Unidas. Por un lado, el Consejo de Derechos Humanos discutía una resolución que planteaba enviar el informe Goldstone al csonu para obligar al cumplimiento de las recomendaciones del reporte, o en caso extremo, para que interviniera la Corte Penal Internacional, algo que México reconocía como improbable. ${ }^{60}$ Por otro, México se encontraba en pleno acercamiento a las economías de Oriente Medio, pues en 2008 Israel había sido su socio regional más importante, ${ }^{61}$ y una votación a favor en el Consejo de Derechos Humanos lo hubiera obligado como miembro no permanente del csonu a definir ahí una postura acorde. ${ }^{62}$ En esas condiciones, México se abstuvo en la votación en el Consejo de Derechos Humanos y meses después ajustó su votación en la AGONU. Como corolario, Goldstone se retractó parcialmente de su informe en 2011, aunque pronto sus colaboradores argumentaron la validez del documento. ${ }^{63}$

${ }^{59}$ Idem.

${ }^{60}$ Véase Agencia EFE, "México considera que el informe Goldstone es «objetivo y completo»", 20 de octubre de 2009, en http:/ /www.palestinalibre.org/articulo. php?a=18695 y http://www.protocolo.com.mx/internacional/israel-y-mexico-reafirman-cooperacion-e-intercambio-economico/, consultado el 24.X.2016.

61 Como consta en la SRE, "México e Israel reafirman sus lazos de cooperación e intercambio económico", comunicado 295, 19 de octubre de 2009, en http:/ / calderon.presidencia.gob.mx/2009/10/mexico-e-israel-reafirman-sus-lazos-de-cooperacion-e-intercambio-economico/, consultado el 24.X.2016.

62 Véase Ministerio de Relaciones Exteriores de Israel, "Israel-Mexico: The fourth policy dialogue", 19 de octubre de 2009, en http://mfa.gov.il/MFA/ForeignPolicy/Bilateral/Pages/Israel-Mexico_fourth_policy_dialogue_19-Aug-2009. aspx, consultado el 24.X.2016.

${ }^{63}$ Cf. R. Falk, Is There a Court for Gaza?, La Haya, Asser Press, 2012, pp. 83-104. 
El caso de Líbano, controversia alta, media y baja

En el periodo de estudio, la AGONU solamente aprobó una resolución en cada uno de los siguientes dos temas: ataques israelíes contra Líbano y sus consecuencias (1996) ${ }^{64}$ y la situación de derechos humanos creada por las recientes operaciones militares israelíes en el Líbano (2006). ${ }^{65}$ México se abstuvo en ambos casos (véase gráfica 7).

\section{GRÁFICA 7}

El caso de Líbano

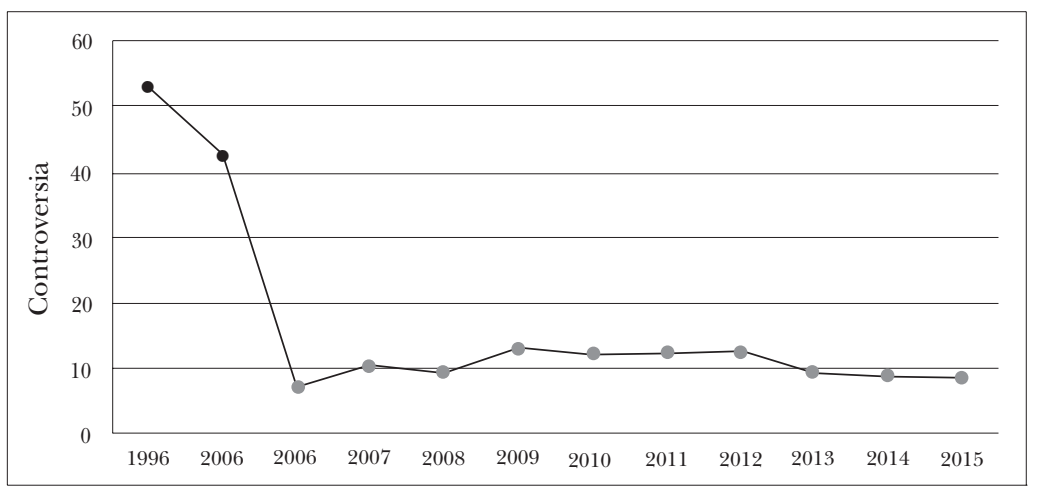

La primera resolución se encuadra en el fin de la guerra civil libanesa, que resultó en un incremento en el lanzamiento de cohetes de Hezbolá contra Israel, con las consecuentes represalias. En 1990, se registraron 19 lanzamientos; en 1991, subieron a 52; aumentaron a 63, en 1992; fueron 158, en 1993; se incrementaron a

${ }^{64}$ AGONU, "The Israeli military attacks against Lebanon and their consequences A/RES/50/22C", 1996, en http://www.un.org/documents/ga/res/50/ares50 -22c.htm, consultado el 21.VI.2016.

65 AGONU, "La situación de los derechos humanos creada por las recientes operaciones militares israelíes en el Líbano A/RES/61/154”, 2007, en https:// documents-dds-ny.un.org/doc/UNDOC/GEN/N06/503/70/PDF/N0650370. pdf?OpenElement, consultado el 21.VI.2016. 
187, en 1994; y llegaron a 344, en 1995. Israel respondió asesinando al Secretario General de Hezbolá Abbas Musawi en 1992 y con dos campañas aéreas y de artillería: la "Operación rendición de cuentas" en julio de 1993 y "Uvas de ira" en abril de $1996 .{ }^{66}$ Durante la segunda campaña, tuvo lugar un ataque a las instalaciones de la Fuerza Provisional de las Naciones Unidas en el Líbano (UNIFIL, por sus siglas en inglés), en Qana. Fue particularmente mediático, ya que hubo alrededor de 100 víctimas civiles que habían buscado refugio en esa localidad. ${ }^{67}$ Ése fue el incidente que causó la resolución. El punto controvertido fue la condena a los ataques israelíes, sin mencionar los cohetes lanzados desde Líbano. Esto lo resaltó el delegado turco al explicar la abstención de su país. Canadá, Venezuela, y Malta explicaron sus abstenciones, lamentando que no se hubiera logrado un texto "balanceado". Trinidad y Tobago, que votó a favor, estuvo de acuerdo con que el texto pudo haberse mejorado. 68

La segunda resolución se aprobó diez años después como consecuencia de la Guerra de Líbano e Israel de 2006. El 12 de julio de ese año, Hezbolá atacó una patrulla israelí matando a tres soldados y capturando a dos. La maniobra (similar a una emprendida en 2004 con resultados favorables) pretendía iniciar negociaciones indirectas con Israel para el intercambio de prisioneros libaneses por soldados israelíes. Sin embargo, las Fuerzas de defensa de Israel reaccionaron bombardeando al día siguiente el aeropuerto de Beirut e imponiendo un bloqueo terrestre, aéreo y naval en Líbano, a lo que siguieron ataques a la infraestructura militar y civil con el

${ }^{66}$ Esta segunda operación se dio después del asesinato de Rabin, en noviembre de 1995, y de las bombas de Hamás y la Jihad Islámica en Tel Aviv, Jerusalén y Ashkelon, que provocaron la muerte de 60 personas, aproximadamente, en febrero y marzo de 1996. Consúltese el trabajo de S. Murden, "Understanding Israel's long conflict in Lebanon: The search for an alternative approach to security during the peace process", British Journal of Middle Eastern Studies, vol. 27, núm. 1, 2000, pp. 25-47.

67 Cf. W. M. Reisman, "The lessons of Qana”, Faculty Scholarship Series, Paper 970, 1997, pp. 381-399.

${ }^{68}$ AGONU, "Ataques israelíes contra Líbano y sus consecuencias A/50/PV.117”, 1996, en http://repository.un.org/bitstream/handle/11176/209337/A_50_PV.11 7-ES.pdf?sequence=5\&isAllowed=y, consultado el 21.VI.2016. 
propósito expreso de terminar con la guerrilla. Hezbolá, a su vez, incrementó considerablemente el lanzamiento de cohetes a centros poblados israelíes. En esas condiciones, y anticipando el cese al fuego, el csonu adoptó la Resolución 1701, fortaleciendo la UNIFIL. En el transcurso de las operaciones militares, cerca de 1200 libaneses murieron y más de 4000 resultaron heridos. Un tercio de las víctimas (la mayoría civiles) era menor de edad. Alrededor de un millón de habitantes fue desplazado por la guerra, 15000 hogares fueron destruidos y la infraestructura del país quedó severamente dañada. En Israel resultaron desplazadas alrededor de 300000 personas, 43 civiles murieron, 117 soldados y miles de hogares fueron dañados. ${ }^{69}$ Estas consecuencias motivaron en la AGONU la resolución que condenó las muertes de los civiles, especialmente de los niños y los ancianos y el uso deliberado de municiones en racimo (muchas no explotaron y quedaron peligrosamente ubicadas en los campos libaneses). ${ }^{70}$

En esta resolución, la razón de las abstenciones, al menos europeas, fue similar. Al explicar su voto, la uE consideró que el texto no trataba las causas que habían llevado a Israel a intervenir (es decir los cohetes de Hezbolá y el secuestro de soldados israelíes), ${ }^{71}$ y no hay registro de que haya habido explicaciones de voto en la sesión. Las dos abstenciones de México son consistentes con la tendencia a retraerse en resoluciones controvertidas y en $2006 \mathrm{su}$ abstención coincidía además (debía hacerlo) con su posición en el csonu, que fue semejante a la europea:

El Gobierno de México ha hecho ya un pronunciamiento sobre el conflicto entre el Líbano e Israel. Sin embargo, deseamos reiterar

${ }^{69}$ K. Makdisi, G. Timur, H. B. Hauck y S. Reigeluth, "UNIFIL II: Emerging and Evolving European Engagement in Lebanon and the Middle East", EuroMeSCo Papers, núm. 76, 2009, pp. 4-39.

70 AGONU, "La situación de los derechos humanos creada por las recientes operaciones militares israelíes en el Líbano A/RES/61/154".

${ }^{71}$ Véase Eu Delegation to the United Nations, "EU Presidency Explanation of Vote- The human rights situation arising from recent Israeli military operations in Lebanon", 2006, en http://eu-un.europa.eu/eu-presidency-explanation-ofvote-the-human-rights-situation-arising-from-recent-israeli-military-operations-inlebanon/, consultado el 21.VI.2016. 
nuestra condena a las acciones de provocación de fuerzas irregulares libanesas que precipitaron esta crisis, así como el uso desproporcionado de la fuerza, que ha ocasionado la destrucción de infraestructura fundamental de uso civil y más de medio millar de víctimas civiles en el Líbano y la Franja de Gaza. ${ }^{72}$

El resto de las resoluciones, votadas por México a favor, tratan el tema "Derrame de petróleo en las costas libanesas". Entre los ataques a la infraestructura libanesa durante el conflicto de 2006, el bombardeo a la planta generadora de electricidad de Jiyyeh, situada a 30 kilómetros al sur de Beirut en la costa, resultó en el derrame de alrededor de 35000 toneladas de petróleo, de las cuales 15000 llegaron al océano. ${ }^{73}$ La marea negra puso gravemente en riesgo la especie de tortugas protegidas que en ese mes desovaban en Líbano y causó la muerte de aves migratorias y sedentarias. La industria pesquera se detuvo completamente y al menos 22 áreas de la costa libanesa se vieron contaminadas. Además, al momento del derrame las corrientes marinas empujaban del sudoeste hacia el norte y noreste, causando que la marea negra se propagara primero a Siria y luego a Turquía y Chipre. ${ }^{74}$

Una vez resuelto el conflicto, la AGONU tomó nota del desastre ecológico, exhortando a Israel a indemnizar a Líbano ${ }^{75}$ y alentando a la comunidad internacional a apoyar a éste en sus labores de recuperación medioambiental. ${ }^{76}$ En resoluciones posteriores se creó el Fondo fiduciario para mitigar los efectos del derrame de petróleo

72 Instituto Matías Romero, op. cit., pp. 299-300.

${ }^{73}$ Para poner esto en cabal medida, el derrame de petróleo Exxon Valdez de 1989 fue de alrededor de 40000 toneladas.

${ }^{74}$ Cf. A. A. Takshe, M. Huby, S. Frantzi y J. C. Lovett, "Dealing with pollution from conflict: Analysis of discourses around the 2006 Lebanon oil spill”, Journal of Environmental Management, vol. 91, núm. 4, 2010, pp. 887-896.

${ }^{75}$ En resoluciones posteriores se agregó a Siria como país con derecho a ser indemnizado.

${ }^{76}$ AGONU, "Marea negra en la costa libanesa A/RES/61/194", 2006, en http:/ / www.un.org/es/comun/docs/index.asp?symbol=A/RES/61/194\&referer=http: // www.un.org/depts/dhl/resguide/r61_resolutions_table_es.htm\&Lang=S, consultado el 22.VI.2016. 
en el Mediterráneo Oriental y se cuantificó el daño en 856.4 millones de dólares. ${ }^{77}$

Es de apuntar que la AGONU trató dos consecuencias de la guerra de 2006: una fue la situación de derechos humanos en la población civil, afectada por las operaciones militares israelíes; otra, las repercusiones en el Medio Ambiente por el derrame de petróleo. Fue más fácil lograr consenso condenando las consecuencias en el mar que en las personas (véase supra gráfica 7).

\section{Conclusiones}

Los resultados demuestran que México siempre apoya las resoluciones de controversia baja, que tiende a abstenerse conforme el ICo aumenta y que simplemente no vota en contra, independientemente del partido político en turno. Los votos a favor en resoluciones controvertidas responden a intereses concretos, como lo muestra el caso de la condena al levantamiento del muro "fronterizo" de Israel en un momento en que México buscaba desasociarse de medidas como ésa. Lo mismo sucede con la cuestión nuclear, en que una abstención podría dañar severamente el prestigio de la política exterior de México.

El caso que ilustra la tendencia con mayor claridad es el Golán sirio. En esas resoluciones México votó en los primeros años (como un buen número de países) absteniéndose cuando había mucha controversia y apoyando cuando había poca. Las resoluciones son iguales en fondo pero diferentes en forma, lo que sugiere una votación calculada en términos del comportamiento de los otros y no como resultado de una reflexión sobre el contenido de la resolución (o sobre los principios de política exterior). Otra serie de resoluciones en donde se lee esa tendencia es la Labor del Comité especial encargado de investigar las prácticas israelíes que afecten

77 AGONU, "Marea negra en la costa libanesa A/RES/70/194", 2015, en http:/ / www.un.org/en/ga/search/view_doc.asp?symbol=A/RES/70/194\&referer= http://www.un.org/en/ga/70/resolutions.shtml\&Lang=S, consultado el 22. VI.2016. 
los derechos humanos del pueblo palestino, en cuyas votaciones la posición mexicana no sólo es de comenzar a abstenerse cuando la controversia aumenta (sin importar su paralela apertura a los derechos humanos), sino que continúa haciéndolo una vez incluido como principio constitucional "la protección y promoción de los derechos humanos". En el caso de Líbano la tendencia también se confirma cuando México condena las consecuencias de un mismo conflicto en el mar, pero no en los humanos.

Una variable que influye en el comportamiento de México en la Asamblea General es su participación en el csonu como miembro no permanente. El cambio de voto (a favor por abstención) en los casos del informe Goldstone y la situación de los niños palestinos y la asistencia a esos niños (ambos a consecuencia de la "Operación plomo fundido"), coincide temporalmente con la pertenencia de México al csonu y la posición de la Unión Europea, lo que refuerza la tesis de que la participación en ese órgano aumenta "el escrutinio de las posiciones adoptadas por México en temas de la agenda internacional, con lo que estaría expuesto a presiones de las grandes potencias" ${ }^{78}$ Éste es un fenómeno que Marta Tawil documentó al estudiar cualitativamente la política de México hacia Oriente Medio en un segmento del marco temporal de este artículo. ${ }^{79}$

El análisis de las votaciones de México en la AGONu sobre temas de Oriente Medio/Palestina utilizando el ICo permite comprender y predecir con cierta seguridad la maniobra mexicana basada en sus intereses y conducta pasada, desligando las cuestiones ideológicas y principistas del comportamiento real. Ello podría resultar en una distensión para quienes toman las decisiones,

${ }^{78}$ J. M. Gómez Robledo V., "El Consejo de Seguridad en la política exterior mexicana”, en R. Dondisch (coord.), México en el Consejo de Seguridad de la ONU. La historia tras bambalinas, México, Debate, 2012, p. 27.

${ }^{79}$ Específicamente, la académica concluye que "el factor explicativo de mayor peso en este caso parecerían ser las presiones del sistema internacional (las relaciones con Washington) filtradas por la predisposición que tienen la clase gobernante, encabezada por el Presidente de la República, y los tomadores de decisión en México y Washington, de interpretar los acontecimientos de Medio Oriente según su propia familiaridad con la región y a través del prisma de sus prejuicios y preferencias" (art. cit., p. 703). 
pues en momentos de tensión entre discursos e intereses, los decisores podrán concentrarse en definir y perseguir activamente estos últimos y, por supuesto, en adecuar los primeros.

\section{BibLIOGRAFÍA}

Agencia EFE, "México considera que el informe Goldstone es «objetivo y completo»", 20 de octubre de 2009, en http:/ /www.palestinalibre.org / articulo.php?a 18695 y http: / $/$ www.protocolo.com.mx/internacional /israel-y-mexico-reafirman-cooperacion-e-intercambio-economico/

AGONU: Asamblea general de la onU, "Respeto y aplicación de los derechos humanos en los territorios ocupados A/RES/2443 (XXIII)", 1968, en https://unispal.un.org/DPA/DPR/unispal.nsf/0/1FE2116 573C8CFBE852560DF000ED05D

"La situación en el Oriente Medio; El Golán sirio ocupado A/ RES/37/123", 1982, en http://www.un.org/en/ga/search/view_ doc.asp?symbol=A/RES/37/123\&referer=http:/ /www.un.org/ depts/dhl/resguide/r37_resolutions_table_eng.htm\&Lang=S

, "El riesgo de proliferación nuclear en el Medio Oriente A/49/ PV.90", 1994, en https://documentsddsny.un.org/doc/UNDOC/ GEN/N94/874/79/PDF/N9487479.pdf?OpenElement

, "El riesgo de proliferación en el Oriente Medio A/RES/49/78", 1994, en http://www.un.org/es/comun/docs/?symbol=A/RES/49/78 , "Labor del Comité especial encargado de investigar las prácticas israelíes que afecten a los derechos humanos del pueblo palestino y otros habitantes árabes de los territorios ocupados A/RES/49/36", 1994, en http://www.un.org/documents/ga/res/49/a49r036.htm

, "El riesgo de proliferación nuclear en el Oriente Medio A/50/ PV.90", 1995, en https://documentsddsny.un.org/doc/UNDOC/ GEN/N95/870/13/PDF/N9587013.pdf?OpenElement , "Ataques israelíes contra Líbano y sus consecuencias A/50/ PV.117”, 1996, en http://repository.un.org/bitstream/handle/11176 /209337/A_50_PV.117-ES.pdf?sequence=5\&isAllowed=y

_ RES/51/48", 1996, en http://www.un.org/es/comun/docs/index. 
asp?symbol=A/RES/51/48\&referer=http:/ / www.un.org/es /documents $/ \mathrm{ag} / \mathrm{res} / 51 /$ list51.htm\&Lang=S

, "General debate on all disarmament and international security items A/C.1/51/PV.12”, 1996, en https://documents-dds-ny.un.org /doc/UNDOC/GEN/N96/866/11/PDF/N9686611.pdf?OpenEle ment

, "The Israeli military attacks against Lebanon and their consequences A/RES/50/22C", 1996, en http://www.un.org/documents/ $\mathrm{ga} / \mathrm{res} / 50 / \operatorname{ares} 50-22 \mathrm{c} . \mathrm{htm}$

, "68 sesión plenaria A/52/PV.68”, 1997, en https:/ / documentsdds-ny.un.org/doc/UNDOC/GEN/N97/867/25/PDF/N9786725. pdf?OpenElement

, “69a sesión plenaria A/52/PV.69”, 1997, en http:/ /www.un.org/ en/ga/search/view_doc.asp?symbol=A/52/PV.69\&referer=http: / / www.un.org/depts/dhl/resguide/r52_resolutions_table_eng. htm\&Lang=S

, "Labor del Comité especial encargado de investigar las prácticas israelíes que afecten a los derechos humanos del pueblo palestino y otros habitantes árabes de los territorios ocupados A/RES/55/130", 2001, en http:/ / repository.un.org/bitstream/handle/11176/153515 /A_RES_55_130-ES.pdf?sequence=6\&isAllowed=y

— A/RES/57/188”, 2002, en https://documents-dds-ny.un.org/doc/ UNDOC/GEN/N02/550/73/PDF/N0255073.pdf

, “A/ES-10/PV.23”, 2003, en https://documents-dds-ny.un.org/ doc/UNDOC/GEN/N03/644/30/PDF/N0364430.pdf

, "La situación de los niños palestinos y la asistencia a esos niños A/RES/58/155", 2003, en https://documents-dds-ny.un.org/doc/ UNDOC/GEN/N03/503/91/PDF/N0350391.pdf

, "La situación de los niños palestinos y la asistencia a esos niños A/RES/59/173”, 2004, en https://documents-dds-ny.un.org/doc/ UNDOC/GEN/N04/486/67/PDF/N0448667.pdf

, "Marea negra en la costa libanesa A/RES/61/194", 2006, en http: / / www.un.org/es / comun/docs/index.asp?symbol=A/ RES/61/194\&referer=http:/ /www.un.org/depts/dhl/resguide/r61_ resolutions_table_es.htm\&Lang=S 
, "La situación de los derechos humanos creada por las recientes operaciones militares israelíes en el Líbano A/RES/61/154”, 2007, en https://documents-dds-ny.un.org/doc/UNDOC/GEN/N06/503 /70/PDF/N0650370.pdf?OpenElement

, "Labor del Comité especial encargado de investigar las prácticas israelíes que afecten a los derechos humanos del pueblo palestino y otros habitantes árabes de los territorios ocupados A/RES/64/91", 2009, en https://unispal.un.org/DPA/DPR/unispal.nsf/0/544BEB0 6378BA234852576B700700B02

, "Seguimiento del informe de la Misión de Investigación de las Naciones Unidas sobre el conflicto en Gaza A/64/PV.39”, 2009 en http://www.un.org/en/ga/search/view_doc.asp?symbol=A/64/PV. 39\&referer=http://www.un.org/en/ga/64/resolutions.shtml\& Lang=S

— - "Seguimiento del informe de la Misión de Investigación de las Naciones Unidas sobre el Conflicto de Gaza A/RES/64/10”, 2009, en http://www.un.org/en/ga/search/view_doc.asp?symbol=A/RES /64/10\&referer=http:/ / www.un.org/en/ga/64/resolutions.shtml \&Lang $=\mathrm{S}$

, "Segundo seguimiento del informe de la Misión de Investigación de las Naciones Unidas sobre el Conflicto de Gaza A/RES/64 /254", 2010, en http:/ / www.un.org/en/ga/search/view_doc.asp?sym bol=A/RES/64/254\&referer $=/$ english $/ \& L a n g=S$

- "Labor del Comité especial encargado de investigar las prácticas israelíes que afecten a los derechos humanos del pueblo palestino y otros habitantes árabes de los territorios ocupados A/RES/67/118", 2012, en https://unispal.un.org/DPA/DPR/unispal.nsf/0/F5E36EFEC44C5E9585257AF60059267A

— ,El Golán sirio A/RES/69/25", 2014, en http://www.un.org/ es/comun/docs/?symbol=A/RES/69/25

— , "El Golán sirio ocupado A/RES/69/94", 2014, en http://www. un.org/es/comun/docs/?symbol=A/RES/69/94

, "El riesgo de proliferación nuclear en el Oriente Medio A/ RES/69/78", 2014, en http://www.un.org/es/comun/docs/?symbol $=\mathrm{A} / \mathrm{RES} / 69 / 78$

, "Labor del Comité especial encargado de investigar las prácticas israelíes que afecten a los derechos humanos del pueblo palesti- 
no y otros habitantes árabes de los territorios ocupados A/RES/ 69/90", 2014, en http://www.un.org/en/ga/search/view_doc.asp?sy $\mathrm{mbol}=\mathrm{A} / \mathrm{RES} / 69 / 90$

—_, "Marea negra en la costa libanesa A/RES/70/194", 2015, en http://www.un.org/en/ga/search/view_doc.asp?symbol=A/RES/ 70/194\&referer=http:/ / www.un.org/en/ga/70/resolutions.shtml \&Lang $=\mathrm{S}$

American Jewish Committee, "One sided: The relentless campaign against Israel in the United Nations; A report on 2004-2005 General Assembly resolutions on the Arab-Israeli conflict”, Nueva York, 2005, en http://www.ajc.org/atf/cf/\% 7B42D75369-D582-4380-8395D25925B85EAF\%7D/One_Sided_59th_Session_UNGA.pdf

Annan, Kofi, "In larger freedom A/59/2005", 21 de marzo de 2005, en http://www.un.org/en/ga/search/view_doc.asp?symbol=A/59/ 2005

Bailey, Michael, Anton Strezhnev y Eric Voeten, "Estimating Dynamic State Preferences from United Nations Voting Data", Journal of Conflict Resolution, 8 de febrero de 2015, pp. 1-36.

Baker, Matt, "Migration Management in North America”, en Martin Geiger y Antoine Pécoud (eds.), The Politics of International Migration Management, Londres, Palgrave Mcmillan, 2010, pp. 271-294.

Bard, Mitchell, "West Bank Security Fence: Background and Overview", Jewish Virtual Library, 2016, en http://www.jewishvirtuallibrary.org/ jsource/Peace/fence.html

Bellany, Ian, Curbing the Spread of Nuclear Weapons, Manchester, University Press, 2006.

Centro de información onu, "México y la onU", 2004, en http://www.cinu. org.mx/onu/mexico.htm

Constitución Política de los Estados Unidos Mexicanos, artículo 89, México, Diario Oficial de la Federación, última reforma publicada el 27.I.2016.

Covarrubias Velasco, Ana, "Los principios y la política exterior de México”, en Jorge A. Schiavon, Daniela Spenser y Mario Vásquez Olivera (eds.), En busca de una nación soberana. Relaciones internacionales de México, siglos XIX y XX, México, CIDE y Secretaría de Relaciones Exteriores, 2006, pp. 387-422.

CSONU: Consejo de Seguridad de la onu, "Resolution 497”, 1981, en https:/ / documents-dds-ny.un.org/doc/RESOLUTION/GEN/NR0/418/84/ IMG/NR041884.pdf?OpenElement 
EU Delegation to the United Nations, "EU Presidency Statement - Situation of and assistance to Palestinian children", 2004, en http://eu-un.europa.eu/eu-presidency-statement-situation-of-and-assistance-to-palestinian-children/

EU Delegation to the United Nations, "Eu Presidency Explanation of VoteThe human rights situation arising from recent Israeli military operations in Lebanon", 2006, en http://eu-un.europa.eu/eu-presidency -explanation-of-vote-the-human-rights-situation-arising-from-recentisraeli-military-operations-in-lebanon/

Falk, Richard, Is There a Court for Gaza?, La Haya, Asser Press, 2012.

Gómez Robledo V., Juan Manuel, "El Consejo de Seguridad en la política exterior mexicana”, en Roberto Dondisch (coord.), México en el Consejo de Seguridad de la onU. La historia tras bambalinas, México, Debate, 2012.

If Americans Knew, "Israelis and Palestinians killed in the current violence”, en http://www.ifamericansknew.org/stat/deaths.html

Instituto Matías Romero, Voz de México en el Consejo de Seguridad de la ONU 1946-2008, México, Secretaría de Relaciones Exteriores, t. 2, 2009.

Kim, Soo Yeon y Bruce Russett, "The new politics of voting alignment in the United Nations General Assembly", International Organization, vol. 50, núm. 4, 1996, pp. 629-652.

Makdisi, Karim, Göksel Timur, Hans Bastian Hauck y Stuart Reigeluth, "UNIFIL II: Emerging and Evolving European Engagement in Lebanon and the Middle East", EuroMeSCo Papers, núm. 76, 2009, pp. 4-39.

Marín Bosch, Miguel, "México en las negociaciones de desarme: la Conferencia de Desarme de Ginebra”, Revista Mexicana de Politica Exterior, noviembre-febrero de 2001-2002, pp. 43-64.

- Votos y vetos en la Asamblea General de las Naciones Unidas, México, Fondo de Cultura Económica, 2004.

- Votes Count: A Compilation of United Nations General Assembly (UNGA) resolutions and Votes of Member States, Desarmex, vol. 1, 2012, en http:/ / desarmex.org/portal/

—, "Relatos e historias en México", Editorial Raíces S.A. de C.V., 2015.

Miller, Todd y Gabriel Mathew Schivone, "Why is an Israeli Defense Contractor Building a «Virtual Wall» in the Arizona Desert?", The Nation, 
2015, en http://www.thenation.com/article/why-israeli-defense-contractor-building-virtual-wall-arizona-desert/

Ministerio de Relaciones Exteriores de Israel, "Israel-Mexico: The fourth policy dialogue", 19 de octubre de 2009, en http://mfa.gov.il/MFA/ ForeignPolicy/Bilateral/Pages/Israel-Mexico_fourth_policy_ dialogue_19-Aug-2009.aspx

Murden, Simon, "Understanding Israel's long conflict in Lebanon: The search for an alternative approach to security during the peace process”, British Journal of Middle Eastern Studies, vol. 27, núm. 1, 2000, pp. $25-47$.

Ordóñez, Andrés, De los avatares de la soberanía. Tradición hispánica y pensamiento político en la vida internacional de México, México, Secretaría de Relaciones Exteriores, 2005.

Rabinovich, Itamar, Lingering Conflict : Israel, The Arabs, and the Middle East 1948-2012, Washington, DC, Brookings Institution Press, 2012.

Reisman, W. Michael, “The lessons of Qana”, Faculty Scholarship Series, Paper 970, 1997, pp. 381-399.

Saltalamacchia Ziccardi, Natalia y Ana Covarrubias Velasco, "La dimensión internacional de la reforma de derechos humanos: antecedentes históricos”, en Miguel Carbonell y Pedro Salazar (coords.), La reforma constitucional de derechos humanos: un nuevo paradigma, México, Instituto de Investigaciones Jurídicas UNAM, 2011, pp. 1-38.

SRE: Secretaría de Relaciones Exteriores, "México e Israel reafirman sus lazos de cooperación e intercambio económico", comunicado 295, 19 de octubre de 2009, en http:/ / calderon.presidencia.gob.mx/2009/10 /mexico-e-israel-reafirman-sus-lazos-de-cooperacion-e-intercambioeconomico/

Takshe, Aseel A., Meg Huby, Sofia Frantzi y Jon C. Lovett, "Dealing with pollution from conflict: Analysis of discourses around the 2006 Lebanon oil spill”, Journal of Environmental Management, vol. 91, núm. 4, 2010, pp. 887-896.

Tawil, Marta, "México ante Medio Oriente durante el gobierno de Felipe Calderón”, Foro Internacional, núms. 3/4, vol. 53, 2013, pp. 667-706.

Varela, Hilda e Indhira Iasel Sánchez, “África y Medio Oriente”, en Mercedes de Vega (coord.), Historia de las relaciones internacionales de México, 1821-2010, México, Secretaría de Relaciones Exteriores, vol. 7, 2006, pp. 245-250. 
Velázquez Flores, Rafael, “«Pragmatismo principista»: la política exterior de México”, Revista de Relaciones Internacionales de la UNAM, núms. 120/121, 2014-2015, pp. 151-164.

Voeten, Erik, "Resisting the lonely superpower: responses of states in the United Nations to U.S. Dominance”, The Journal of Politics, vol. 66, núm. 3, 2004, pp. 729-754. 